\title{
Perceived Links Between Physical Problems and Stress May Be Clouded by Dissociative Processes
}

\author{
Margaretta E. Kruesi \\ Jeffrey J. Borckardt, PhD \\ Jarred Younger, $\mathrm{PhD}$ \\ Michael R. Nash, PhD \\ Darlene Shaw, $\mathrm{PhD}$
}

\begin{abstract}
This study investigated the relationships between dissociative experiences, somatization and participants' perceptions regarding the contribution of stress to their physical problems. Seventy undergraduate students were administered the Dissociative Experiences Scale (DES; Bernstein \& Putnam, 1986) and a physical symptom checklist which included questions about the frequency and severity of various physical symptoms as well as participants' perceptions of the contribution of stress to their physical symptoms. A significant positive relationship was found between DES scores and self-reported frequency and severity of somatic symptoms. Participants with higher DES scores were less likely to attribute their physical problems to stress than subjects with lower DES scores. [Article copies available for a fee from The Haworth Document Delivery Service: 1-800-HAWORTH. E-mail address: <docdelivery@ haworthpress.com> Website: <http://www.HaworthPress.com> (C) 2004 by The Haworth Press, Inc. All rights reserved.]
\end{abstract}

Margaretta E. Kruesi and Jeffrey J. Borckardt are affiliated with the Medical University of South Carolina.

Jarred Younger is affiliated with Arizona State University.

Michael R. Nash is affiliated with the University of Tennessee, Knoxville.

Darlene Shaw is affiliated with the Medical University of South Carolina.

Address correspondence to: Jeffrey J. Borckardt, PhD, Department of Psychiatry and Behavioral Sciences, Medical University of South Carolina, CAPS-30 Bee Street, Charleston, SC 29425 (E-mail: borckard@ musc.edu).

Journal of Trauma \& Dissociation, Vol. 5(4) 2004

http://www.haworthpress.com/web/JTD

(C) 2004 by The Haworth Press, Inc. All rights reserved.

Digital Object Identifier: 10.1300/J229v05n04_08 
KEYWORDS. Dissociation, somatization, stress, physical symptoms

\section{INTRODUCTION}

Dissociation and somatization have been regarded as possible self-regulatory coping behaviors (Farley \& Barkan, 1997), and there have been numerous investigations into the relationship between them (Nijenhuis, 2000; Nijenhuis et al., 1999). There appears to be a positive relationship between dissociation and somatization (Saxe et al., 1994; Engel, Walker, \& Katon, 1996; Norton \& Ross, 1990).

Much research has also been done on the links between stress and physical problems. Lower quality of life and higher levels of emotional stress have been associated with somatic symptoms (Ladwig, Marten-Mittag, Erazo \& Guendel, 2002). DeLongis, Folkman and Lazarus (1988) found that increases in stressful daily hassles are associated with a decline in health and more negative mood. Reynolds, O'Koon, Papademetriou, Szcygiel and Grant (2001) report that somatic complaints are very common among chronically and severely stressed youth, whereas other internalizing symptoms (e.g., crying, low self-esteem) are less common.

While the interface between stress, health and somatic complaints continues to be an evolving area of research, there is a lack of information available about participants' perceptions of the contributions of stress, anxiety and worry to their own physical problems. More specifically, we do not know to what extent dissociation plays a role in individuals' attributional processes regarding their own somatic complaints. If we adopt the perspective that dissociation is a coping strategy that involves splitting-off of distressing experience, we might expect participants with higher DES scores to be less likely to link these affective states to somatic complaints.

The present study sought to examine the relationship between reported frequency and severity of various somatic complaints and dissociative experiences. Additionally, this study sought to determine if dissociative experiences are associated with participants' tendency to link stress with their physical symptoms.

\section{METHODS}

\section{Participants}

Participants were 70 undergraduates at the University of Tennessee at Knoxville enrolled in introductory psychology classes. There were 
34 males and 36 females with a mean age of 19.59. Participants volunteered to participate in the study and received extra credit for their participation.

\section{Materials}

Dissociative Experiences. Dissociative experiences were measured with the Dissociative Experiences Scale (Bernstein \& Putnam, 1986). The DES consists of 28 items that describe various dissociative experiences. After each item, the participants indicate what percent of the time they have the experience on a scale ranging from $0 \%$ to $100 \%$.

Somatization. Somatization was measured using an original checklist of 42 common somatic complaints. Examples of symptoms/items are headache, vomiting, muscle tension, fatigue or weakness, and numbness or tingling. For each symptom, participants indicated on a 5-point Likert scale (0-4) the frequency of occurrence of each symptom $(0=\mathrm{I}$ have never had this problem, to $4=$ more than four times a month). Next, participants indicated the severity of each symptom on a 5 -point Likert $(0=$ never a problem at all, to $4=$ huge negative impact on my life). Finally, participants were asked to indicate if they have each symptom when they feel "stressed, anxious, frightened or worried" by making a checkmark in a box next to each item. The total number of checkmarks represented the number of physical symptoms participants link to stress, anxiety or worry and thus this number was used as the level of participants' perceived contribution of stress to their physical symptoms (called the linking variable). The physical symptom frequency and severity scales demonstrated good internal consistency reliability (alphas $=.88$ and .88 ) and the internal consistency reliability for perceived contributions of stress to physical symptoms was good (alpha $=.87$ ).

The Somatization sub-scale of the Symptom Checklist-90R (SCL-90R; Derogatis \& Lazarus, 1994) was used to provide a validity reference for the somatization scale described above. The SCL-90R is a symptom checklist consisting of 90 items that load into nine subscale factors. The somatic problem frequency scale (described above) was correlated with the Somatization subscale of the SCL-90R $(r=.70, p<.001)$ as was the severity scale $(r=.63, p<.001)$ supporting the validity of the physical symptom checklist as a measure of somatization. 


\section{Procedure}

Participants came to a research lab individually and were seated at a table where they signed the informed consent form and completed the DES, SCL-90R and the somatization checklist. The questionnaire order was randomized and participants were blind to the hypotheses of the study. Upon completion of the questionnaires, participants were thanked and de-briefed.

\section{RESULTS}

Frequency and severity of somatic complaints were positively correlated with DES scores. Participants with higher DES scores reported that they had physical symptoms more frequently than participants with lower DES scores and they were more bothered by them $(r=.38, p<$ $.01 ; r=.39, p<.01$, respectively). Frequency and severity were also highly correlated with participants' tendency to link stress to their physical problems, however, these variables are highly interdependent. Table 1 shows the correlations between dependent variables in the study.

While dissociative experiences did not appear to predict the linking variable, a significant relationship between the two would be predicated on the presence of at least some physical problems (i.e., somatic problems have to first exist in order for participants to attribute them to stress). To more accurately test the relationship between dissociation and linking, multiple regressions were used, controlling for the effects of symptom frequency and severity. The model was significant $(F(3,61)=$ $30.74, p<.0001$ ) and each of the variables uniquely predicted the linking variable despite being related to each other. Dissociative experi-

TABLE 1. Correlations (and $p$-values) between dependent measures in the study: Dissociative Experiences Scale (DES), frequency of somatic problems, severity of somatic problems, and number of somatic complaints linked to stress (Link).

\begin{tabular}{l|cccc} 
& DES & Frequency & Severity & Link \\
\hline DES & - & $r=.38$ & $r=.39$ & $r=.15$ \\
Frequency & $p=.002$ & - & $r=.83$ & $r=.69$ \\
Severity & $p=.002$ & $p<.001$ & - & $r=.74$ \\
Link & ns & $p<.001$ & $p<.001$ & - \\
\hline
\end{tabular}


ences significantly predicted the linking variable over and above other variables in the model. As expected, the relationship between dissociation and the linking variable is negative suggesting that participants with high dissociative tendencies were less likely to attribute their physical symptoms to stress. Regression model parameters are presented in Table 2.

\section{DISCUSSION}

Consistent with previous research, a positive relationship was found between somatic symptoms and dissociation. Additionally, a negative relationship was found between dissociation and the perceived relationship between stress and physical symptoms. Participants who report higher levels of dissociation were less likely to believe that stress or anxiety contributed to their physical symptoms. Therefore, individuals with a high tendency for dissociative experiences (as compared to low dissociators) report more somatic complaints while also believing these complaints to have less to do with their psychological state.

While the limited use of dissociative strategies lies in the range of healthy adaptation to stress (e.g., imagining a positive event to avoid feeling the pain of long-distance running), over-reliance of any one coping mechanism may be unhealthy. If dissociative defenses are over-employed early in an individual's psychological development, such defenses may develop into a rigid coping style. As evidenced by this and prior research, part of this coping style may be the somatization of psychological anxiety. At the same time, however, the very nature of dissociation would prevent somatic complaints from being connected to psychological states, else the defense would be unsuccessful. Therefore, a com-

TABLE 2. Parameters from the regression equation predicting participants' tendency to link stress to somatic complaints using frequency and severity of somatic complaints, and dissociative experiences (DES) as predictors $(F(3,61)=$ 30.74, $p<.0001)$.

\begin{tabular}{lccc}
\hline Variable in Model & Std. B & t-value & p-value \\
\hline (Constant) & - & 0.98 & .33 \\
Frequency & .30 & 2.00 & .05 \\
Severity & .59 & 3.96 & $<.0001$ \\
DES & -.23 & -2.56 & .013 \\
\hline
\end{tabular}


plete dissociation of psychological trauma or stress might involve (1) the somatization of that stress, and (2) a complete delineation between the two. Both facets of this mechanism are reflected in the results of the present study.

The results of the present study do not identify casual relationships between measured variables and, therefore, may be explained by different models. For example, early trauma and continuing high stress may independently lead to both (1) frequency of physiological complaints, and (2) dissociative coping styles. Further studies are needed in order to determine the directionality of these relationships. However, it is clinically relevant to note the initial relationships found here between dissociative tendencies, high somatic complaints, and low belief in the connection between psychological and physiological problems. The co-occurrence of these phenomena provides more opportunities for intervention. For example, patients may benefit from behavioral therapies that teach about the connections between stress and physical maladies. These related phenomena may be used diagnostically as well; a clinical presentation of a patient complaining of multiple vague physical symptoms while denying that the symptoms to do with stress may suggest of dissociative tendencies, which could inform psychotherapy interventions. Future studies should expand on these initial findings by enlarging sample size, adding measures of chronic and acute stress, and exploring casual models for these multiple related phenomena.

\section{REFERENCES}

Bernstein, E.M., \& Putnam, F.W. (1986). Development, reliability and validity of a dissociation scale. Journal of Nervous and Mental Disease, 174, 725-735.

DeLongis, A., Folkman, S., \& Lazarus, R.S. (1988). The impact of daily stress on health and mood: Psychological and social resources as mediators. Journal of Personality and Social Psychology, 54, 386-395.

Derogatis, L. R., \& Lazarus, L. (1994). SCL-90-R, brief symptom inventory, and matching clinical rating scales. In M.E. Maruish, (Ed.), The use of psychological testing for treatment planning and outcome assessment (pp. 217-248) Hillsdale, NJ: Lawrence Erlbaum Associates.

Engel, C.C., \& Walker, E.A., \& Katon, W.J., (1996). Factors related to dissociation among patients with gastrointestinal complaints. Journal of Psychosomatic Research, 40, 643-653.

Farley, M. \& Barkan, H. (1997). Somatization, dissociation, and tension reducing behaviors in psychiatric outpatients. Psychotherapy and Psychosomatics, 66, 133-140. 
Ladwig, K.H., Marten-Mittag, B., Erazo, N., \& Guendel, H. (2001). Identifying somatization disorder in a population-based health examination survey: Psychosocial burden and gender differences. Psychosomatics, 42, 511-518.

Nijenhuis, E.R.S. (2000). Somatoform dissociation: Major symptoms of dissociative disorders. Journal of Trauma \& Dissociation, 1(4), 7-32.

Nijenhuis, E.R.S., van Dyck, R., Spinhoven, P., van der Hart, O., Chatrou, M., Vanderlinden, J., \& Moene, F. (1999). Somatoform dissociation discriminates among diagnostic categories over and above general psychopathology. Australian \& New Zealand Journal of Psychiatry, 33, 511-520.

Norton, R.G., \& Ross, C.A., (1990). Factors that predict scores on the Dissociative Experiences Scale. Journal of Clinical Psychology, 46, 273-277.

Reynolds, L.K., O’ Koon, J.H., Papademetriou, E., Szczygiel, S., \& Grant, K.E. (2001). Stress and somatic complaints in low-income urban adolescents. Journal of Youth \& Adolescence, 30, 499-514.

Saxe, G.N., Chinman, G., Berkowitz, R., Hall, K., Lieberg, G., Schwartz, J., \& van der Kolk, B.A. (1994). Somatization in patients with dissociative disorders. American Journal of Psychiatry, 151, 1329-1334.

RECEIVED: $10 / 31 / 03$

REVISED: $12 / 19 / 03$

$01 / 20 / 04$

ACCEPTED: 01/21/04 